\title{
Egyptian Neonatal Safety Training Network: a dream to improve patient safety culture in Egyptian neonatal intensive care units
}

\author{
Safaa ELMeneza ${ }^{1}$ \\ Paediatrics Department, Faculty of Medicine for Girls, Al-Azhar University, Cairo, Egypt (Correspondence to: Safaa ElMeneza: safaa5@hotmail.com).
}

\begin{abstract}
Background: Patient safety is fundamental to upholding the quality of health care. Health-care workers in neonatal intensive care units (NICUs) face daily challenges to sustain safe care for their patients and to counteract medical errors.

Aims: The objectives were to develop the Egyptian Neonatal Safety Training Network (ENSTN) to promote safe health care practices in NICUs through training of Health-care workers on PtS and dissemination of a culture for patient safety.

Methods: The ENSTN project accomplishments were completed through 8 work packages. The first package activities were intended to establish standards of knowledge and skills for safe practices in the NICU, develop the course specifications for PtS and develop standards. The remaining packages included: a professional patient safety reporting system and database; cohesive shared education and training in patient safety leadership and research; development of protocols and guidelines to enhance and ensure sustainability of safe practice; dissemination of ENSTN messages; confirmation of quality measures and adequate performance; sustainability of patient safety practices in the NICU; and structuring the management plan and facilitating project activities.

Results: Project outputs included: patient safety standards for NICUs in Arabic and English; 3 patient safety courses for physicians, nurses and other health-care workers the ENSTN electronic reporting system for medical errors and guidelines; and a parent's booklet.

Conclusions: Continuous organized training for health-care workers on patient safety and implementation of ENSTN standards to reduce medical errors in the NICU are needed. We implemented the first confidential patient safety reporting system for NICU.

Keywords: patient safety, neonatal intensive care units, safety training package, Egypt

Citation: ELMeneza S. Egyptian neonatal safety training network: a dream to improve patient safety culture in Egyptian NICUs. East Mediterr Health J. 2020;26(10):1303-1311. https://doi.org/10.26719/emhj.20.034

Received: 01/05/19; accepted: 22/05/19

Copyright ( $\odot$ World Health Organization (WHO) 2020. Open Access. Some rights reserved. This work is available under the CC BY-NC-SA 3.0 IGO license (https://creativecommons.org/licenses/by-nc-sa/3.o/igo)
\end{abstract}

\section{Introduction}

Patient safety (PtS) is core of quality of health care. Health care workers (HCWs) in neonatal intensive care units (NICUs) are facing a daily challenges to sustain safe care for their patients and to counteract medical errors while they are performing complex health care. They act very hard to avoid any level of harm that may affect quality of life in newborn infants. Unfortunately, these attempts are not sufficient to conserve appropriate PtS culture in NICUs and medical errors do occur.

Medical interventions are high risk procedures. Errors are inevitable, but most are preventable. $(1,2)$. The publication of the famous report "To err is human" by the Institute of Medicine of United States of America (USA) was the first to direct attention to the role of the health care system in medical errors. (3). Although the report data seemed to be disappointing due to the number of deaths from medical errors, it considered the groundwork for change in health care systems and in initiating quality improvement. It helped the move to a system-based approach instead of blaming persons.

Patient safety is a serious global public health concern. There is a 1 in 300 chance of a patient being harmed during health care. Patient harm is the 14th leading cause of the global disease burden, comparable to diseases such as TB and malaria (4).

While in hospital, 1 in ten patients is harmed in highincome countries; the harm is caused by a wide range of incidents or adverse events, with nearly $50 \%$ of them being preventable. In 26 studies in low- and middleincome countries, the adverse event rate was around $8 \%$, of which $83 \%$ could have been prevented and $30 \%$ lead to death (4). Approximately $2 / 3$ of all adverse events occur in low-income countries (4). Research in the USA has shown that 251454 inpatients (9.5\%) die annually as a result of medical error. "If medical error was a disease," they concluded, "it would rank as the third leading cause of death in the United States" $(5,6)$.

European data, mostly from European Union Member States, consistently show that medical errors and health care-related adverse events occur in 8-12\% of hospitalizations. Evidence on medical errors shows that $50 \%-70.2 \%$ of such harm can be prevented through comprehensive systematic approaches to PtS (7)

There are few sources of data available in Egypt on type, rate or magnitude of medical error in Egyptian NICUs. Our observations from clinical case reports 
and academic theses provided evidence of harm in our NICUs, but the fear of blame and punishment has led to concealing reporting the adverse events. Additionally, there was no incident reporting system or safety culture to encourage reporting (8).

Quality in health care begins with ensuring safety (9-10). In Europe, PtS depends on effective, sustained policies, programmes and standardized training of health professionals to prevent adverse events, creating networks and information systems focusing on exchange of experience and best practice (11-13).

Our concern is with PtS in NICUs as lack of safety practices has a direct influence on morbidity, mortality, and long-term quality of life. Medical errors are common in NICUs, and frequently result in sentinel and adverse events with harm to patients. These cause ethical and financial burden on the society.

There is lack of training programmes on PtS science. The undergraduate and postgraduate medical programmes do not include PtS courses. Also lack of on-the-job training for physicians, neonatologists, paediatricians and nurses is another the problem hindering the implementation of quality safety standards. There is no leadership or seamless communication which reduces the problems of PtS. Other important problems of concern include the absence of a culture for event recording, root cause analysis and risk management.

The broad objective of the ENSTN was to develop and support the establishment of the Network to promote safe health care practices in NICUs and prevent inadvertent harm to patients as a result of their care. This would be achieved through contribution to learning and training of HCWs such as neonatologists, paediatricians, nurses and medical students on PtS and the dissemination and promotion of a PtS culture.

\section{The specific objectives were:}

- to establish clearly defined standards of knowledge and skills required for safety practice in the NICU in line with international PtS standards;

- to develop course specifications for PtS in the NICU that can be included in the training of health professionals;

- to foster development of a safety culture in NICUs that depends on a system approach, promotes reporting of adverse events and is focused on prevention and learning;

- to modernize the NICU workforce through development of shared education ands training with European partners in scope of PtS by first year and development of protocols, pathways and guidelines;

- to provide effective leadership and team work training in PtS;

- to encourage research into PtS improvement;

- to communicate with parents and relevant stakeholders regarding PtS through regular meetings;

- to develop national standards for NICU safe practice.

\section{Methods}

In order to modernize PtS culture in Egyptian NICUs and promote leadership to oversee changes in the current PtS culture and implement database for medical errors, a grant was submitted to Tempus. Five Egyptian and 3 European universities participated in the project. Al Azhar University was the grant holder and co-beneficiary universities were Liverpool, Tartu, Constanta, Mansoura, Tanta, Suez Canal and Zagazig. The project began in December 2013 and was technically completed in August 2017. It is the expected that the activities will carry on in order to maintain the safety culture.

Nonpartner universities; health ministry physicians and officials; neonatal societies; and private, insurance and teaching hospital staff were invited to attend and share in founding workshops, launching meetings, organizing training workshops and preparation of guidelines.

Our outputs documents were peer reviewed by our European partners and project experts. They was also benchmarked with the international qualifications and standards.

\section{Target groups}

The target groups were: HCWs (physicians, neonatologist, paediatricians, nurses, pharmacists, residents, house officers); students; workers affiliated to partner and nonpartner universities; relevant stakeholders such as the Ministry of Health and Population, nongovernmental organizations; the public, insurance and private hospitals; medical syndicates; and parents who wanted to make a difference in providing PtS culture.

The technical design and steps of the project followed the Tempus guidelines and grant template. This was done by distributing the project activities and tasks into work packages then determining the major deliverables from each work package as well as assigning the roles of the grant holder and beneficiaries in each work package. There was plan for the work, with contingency and nonconformance plans included in the grant agreement.

The project was accomplished through 8 work packages that were designed to achieve the project objectives.

The first work package activities covered establishing standards of knowledge and skills for safety practice in NICU, developing course specifications for PtS in the NICU to be used for training of Egyptian HCWs and developing the PtS standards for the NICU.

The second work package tasks were constructed to develop the first professional NICU PtS reporting system and database to report medical errors and to interact with the reporters. Additionally they aimed to provide educational support through an educational forum in English and Arabic.

The third work package was planned to ensure development of cohesive shared education and training in scope of PtS, leadership and research according to international 
standards. Training considered different learning styles and use interactive learning with feedback to guarantee safety skills acquisitions strengthen knowledge and skills of HCWs. It included case based approach, hand on exercises on simulators. The effect of training was measured by pre- post test and evaluation by the contact sites in their NICU.

The workshops training involved the introduction of PtS science, human factor engineering PtS, basic PtS knowledge and skills, using safety tools in root cause analysis, incident reporting and PtS interventions. Training was organized through integrated workshops in Egypt shared by EU and Egyptian partners as well as training visits in corresponding NICUs of European partners.

Patient safety leadership and research courses were developed. Leadership workshops were conducted to expand the capacity of HCWs to conduct change in PtS culture and included training on clinical and managerial safety leadership as well as communication, time and change management. Research workshops were conducted to expand capacity of HCWs to conduct PtS research.

The fourth work package related to the development of protocols and guidelines to enhance the provision of safety practice in Egyptian partners and to ensure sustainability of safe practice in NICUs. These guidelines were directed towards specific safety problems in the NICU which occur due to lack of knowledge or skills and were prepared by the Egyptian and EU partners with the involvement of stakeholder representatives to ensure their use and sustainability.

The aim of the fifth work package was to disseminate ENSTN messages and to communicate with relevant stakeholders and parents in Egypt. It included activities to approach stakeholders, non-partners, parents of patients and the public in order to develop national NICU PtS standards and to modernize current PtS practices, and to ensure more contributions from parents of patients, stakeholders and the public.

The sixth work package included activities to confirm quality measures and adequate performance and guarantee the achievement of our objectives.

The seventh work package activities were directed at ensuring the sustainability of PtS practice in the NICUs of Egyptian partners after the project was completed.

The eight Work package was established to structure the management plan and to facilitate project activities.

Operational design and the tools used in the project were included in the grant template. We used the Tempus-designed Gantt chart template and logical framework.

All planned activities relating to each work package were listed in the Gantt chart. For each activity, we entered the start date, estimated duration and the end date. We scheduled the activities successively to ensure that dependent activities did not start until the activities they depended on had been completed. The required resources were determined in the most economic way for each activity according to the output and to the target group.

In the logical framework, we included the project objectives set against the activities and outcome/output as well as the evidence for execution of these activities and their relation to the required resources. The expected threats and how to deal with each one were also included.

Although we conducted the survey regarding knowledge and practices before implementation of the project, we did not have data from all partners regarding the effects after the project.

Regarding to the administrative design and ethical consideration of the project, there was a written agreement between Tempus and the grant holder, AlAzhar University, then a mandate and agreements between the grant holder and the beneficiaries. These agreements included the responsibilities, duties, time frame, finances and the role of each body as determined by the grant rules of the European Commission/Tempus.

The grant holder was responsible for all the financial and legal aspects of the project and contact with Tempus. It was also responsible for communicating all the progress as well as arranging for the audit visits during the project life time as well as sustainability activities. The grant holders and the beneficiaries were responsible for executing the project tasks in accordance with the agreement. There was also a managerial committee and an executive committee for the higher project management and executive and working groups at the beneficiary level.

We followed the ethical and confidentiality rules as in the agreements. Also, we implemented the ENSTN policy (one of the project outcomes) regarding the duties, responsibilities and rights of the partners as well as ownership of the database and confidentiality regarding the reporting system.

\section{Results}

\section{Document on patient safety standards for NICU patients in Arabic and English}

This is the required standard of care for safe practice. This document was the aspiration of all neonatologists and HCWs participating in the care of newborn infants. It illustrates the rationale for the needs of medical safety standards and was based on the initial survey. The aim for the standards proposed by the ENSTN was to embrace nearly all health care disciplines and actors in NICUs and endorse a comprehensive, multifaceted approach to preventing and managing the actual and potential risks to PtS in the NICU, and to propose national standards to be adopted by the Ministry of Health and Population, universities and other health care facilities. It describes what is meant by safety and by standards. These standards can be applied to various health care facilities that provide neonatal care. It is important to locate where and why ad- 
verse events occur; starting from delivery rooms, outpatient clinics, private or general hospital NICUs, a variety of events may occur. General PtS standards and specific PtS standards for the neonatal population are available in both Arabic and English versions. These specific standards are exclusive to newborn infants, and are needed to apply safe care in NICUs.

\section{Document for necessary lknowledge, skills behaviour and attitude for safety practice in neonatal intensive care units for all health care workers}

This document covers the attributes and qualities needed regarding the knowledge and the intellectual, professional and behavioural skills that are needed for safe practice in NICU for physicians, nurses, pharmacists and other workers.

\section{Egyptian Neonatal Safety Training Network policy documents}

This document covers the policy and regulations for the ENSTN. There are 2 types of rules for the database. The document also demonstrates the eligibility criteria and establishes the structure and responsibilities of the ENSTN. It displays regulations for the categories of: membership, job descriptions and research, authorship of publications, data ownership, the confidentiality policy and the policy for reporting clinical adverse events. The following were developed:

- 3 PtS courses specifications for NICU HCWs one for physician, one for nurse and one for other HCWs;

- neonatal PtS course specifications for medical staff/ physicians, scientific content, manual of trainers and manual of trainees and power points /presentation for the neonatal PtS course specifications for medical staff to be used during workshops;

- PtS course specifications (Arabic English) for non-medical staff, manual of trainers and trainee and power point presentations;

- PtS course specifications for nurses (English and Arabic) scientific content, manual of trainers and manual of trainees and power points/presentation.

It covers PtS course specifications for medical staff/ physicians, scientific content, the trainers' and trainees' manuals, and the PowerPoint presentations for the neonatal PtS course specifications for medical staff to be used during training workshops.

The PtS course specifications for nurses, other HCWs and non-medical staff were developed in both Arabic and English for the trainers' and trainees' manuals and PowerPoint presentations.
For each course there is scientific content, trainer and trainee manuals and PowerPoint presentations. These include the teaching methods and the curriculum.

The courses concentrate on basic training in safetyrelated issues; an introduction to the science of PtS; basic PtS concepts (e.g. explain adverse events, close calls, systems approach, high reliability organizations), understanding of the human factors engineering PtS and key methods for more effective PtS programmes. The courses also provide more in depth studies on the safety tools: systematic reporting, identifying how to respond to an adverse event and conduct an investigation using root cause analysis and health care failure mode and effect analysis and risk management.

Also included is the concept of PtS interventions and how to implement solutions to improve quality of care and PtS in the NICU. The presenters explain the role of both individuals and systems in improving PtS. The course is structured in 3 modules for the physicians who were instructed to train in the knowledge and skills needed for safe medical practice.

\section{Patient safety leadership course developed; also a manual for trainers and trainees and PowerPoint presentations on scientific content}

This course is composed of 5 modules. The NICU HCWs should understand the communications principles and how these can affect PtS, They need to be competent in managing change and facing conflicts and stress. The aim is to allow neonatologists to modernize the current blaming culture in PtS and promote a culture that facilitates training and the reporting of errors, and implements solutions to prevent errors. The trainee will recognise and have training on the related communication procedures, time and stress management, basic skills for dealing with conflict and reducing resistance to change. They also need to acquire knowledge and skills for motivation and negotiation while understanding true meaning of leadership. They will gain the necessary management skills, audit and ethical issues pertaining to PtS. They should also have knowledge of preventative strategies and prevention of stress in the NICU: thus, trainees will be able to recognize the extent of problems originating from inability to manage the daily work. This training course is also intended to improve the level of care in the NICU regarding safety issues and to harmonize training between participating universities and other stakeholders. It will prepare HCWs to modernize the PtS culture and improve the quality of health care. 


\section{Developed a patient safety research course, and manual of trainers and trainees and PowerPoint presentations on scientific content}

This covers the research methodology course prepared by the ENSTN team. The emergence of new NICU PtS standards suggested by the ENSTN will need effective practice of knowledge, and the ability to conduct root cause analysis and study the solutions in a safe, effective and efficient way before implementation.

It is important for the dissemination of a new PtS culture among HCWs. It comprises 2 modules.

The course concentrates on:

- how to conduct a research paper,

- formulation of research objectives and questions,

- how to write a research paper/manuscript preparation,

- how to review a scientific article,

- how to evaluate articles for publication,

- how to prepare a scientific presentation,

- documents for the incident/event reporting manual.

The booklet helps the HCWs to report data to the ENSTN reporting system and to ensure uniform understanding and operational definitions of the terminology related to medical errors, PtS and degree of harm and severity. It explains incident report data definitions. It shows the basic data that will be reported, how to describe the incidents, staff members, impressions about the incidents and patient details.

\section{Established a patient safety network webpage, reporting system and database for NICU in Arabic and English (www.egyneosafety.net)}

The project webpage covers the incident reporting system in English and Arabic and an educational forum to train on safe practice and encourage participants to exchange experiences. It also disseminates alerts and indicators. It has a parents section and shows the project activities such as workshops and meetings, dissemination activities, project news and a photo gallery. It links to the ENSTN Facebook page and also the YouTube link where educational videos for the project can be accessed. An electronic data entry form has been developed in Arabic and English and a phone application download is available through Google Play.

\section{Developed 15 guidelines with three translated into Arabic}

We developed 15 guidelines in the English language. We translated 3 guidelines into Arabic: to prevent delayed and wrong diagnosis, to prevent falls and dropping of newborn infants in the neonatal nursery, and hearing screening of newborns and infants in the NICU. These can be used by nurses and other HCWs. The developed guidelines comprise:

- to prevent delayed and wrong diagnosis in the NICU;

- for the management of late treatment and how to deal with errors and subsequent events;

- for the prevention of medication errors on the neonatal unit;

- policy for: the identification of a baby (tagging), prevention of baby abduction, action if abduction is suspected;

- hearing screening of newborns and infants in the NICU;

- follow-up of retinopathy of prematurity;

- management of adverse transfusion reactions;

- use of instruments and how to deal with subsequent events;

- guideline on the use of oxygen in the newborn;

- guideline for heel stick (capillary blood sampling);

- guideline for transport and retrieval;

- guideline for exchange transfusion;

- preventing falls and dropping of newborn infants in the neonatal nursery;

- guideline/policy to achieve maximum safety during preparation, processing and administration of parenteral nutrition in newborn infants;

- infection control policies in the NICU.

\section{Developed 6 educational videos for health care workers and parents}

The videos show clinical and procedural skills as well as instruction to physicians and nurses on how to admit cases to the NICU and how to perform necessary invasive clinical procedures that may interfere with safe patient care. They also show how to do perform manoeuvres on newborn infants, e.g. intubation, insertion of chest tube, resuscitation and insertion of long central venous catheter. There are 2 videos showing how errors occur. There is one educational video aimed at the parents to help them prepare for infant discharge from the NICU and to carry out safe care at home. Advertising materials (films) were released aimed at increasing public awareness regarding patient safety culture; we also produced a documentary on the project.

- production of awareness and educational film for the public to improve PtS culture; a project documentary film was also produced;

- dissemination tools: presentation in conferences, brochures, leaflets, 6 newsletters, and media; TV and newspapers;

- document of parents' educational booklet (the document is in Arabic and used mainly for parents. It explains the nature of the NICU, steps for admission and type of care and how to communicate with doc- 
tors and responsible physicians in the hospital and safe medication use);

- PtS team in majority of participating units;

- $\quad$ agreement with related stakeholders;

- sustainability of ENSTN project was attained through a grant from the Research and Technology Academy;

- 34 NICU PtS workshops, 11 NICU PtS leadership workshops, 14 NICU PtS scientific research workshops, 14 NICU incident report workshops were conducted;

- 7 Masters theses and one MD thesis were completed.

\section{Discussion}

The ENSTN addressed the knowledge triangle of education, research and innovation. It is linked to education and has developed partnerships with related stakeholders. The ENSTN project provided a full package of complementary courses and training workshops that increased capacity-building of HCWs in regard to their knowledge and skills in PtS science and incident reporting. Correspondingly, the package increased competence and professional practice in how to act as a team with effective, seamless communication; it led to change in PtS culture and enabled HCWs to investigate the root causes of medical errors and to implement changes that will prevent errors from recurring.

The project is one phase towards filling the gaps in PtS culture in Egyptian NICUs and towards modernizing PtS culture in NICUs. The activities fit within the Egyptian strategy of education as PtS is one of the important priorities of the health care system.

The ENSTN project objectives have been realized. The first work package outputs helped to achieve the wide objective, and specific objectives 1, 2, 3, 4 and 8. The NICU safety standard is one of the important outputs: to our knowledge it is first safety standard in Egypt directed at the neonatal age group. The PtS standards document included the clear, defined, safety standards that are required for proper safe practice in NICUs. It covered the essential knowledge and skills required for safe practice in the NICU. The need for such safety standards has been illustrated in different parts in the world (14-16).

Three PtS course specifications with their related trainer and trainee manuals were established. This supported the needs of different health workers, e.g. physicians/nurses/non-medical staff. The educational tools as scientific content, videos and simulations were provided to improve the skills in neonatal care. The courses will help the sustainability of NICU PtS training and modernization of PtS culture after the lifetime of the project. The need for standardized training and courses was alerted by the World Health Organization (WHO) through medical student curricula (17).

The second work packages output achieved project's wide objective and specific objectives numbers 3 and 8 . We succeeded in developing the ENSTN webpage and incident reporting system in Arabic and English. The online electronic network boosts event recording. The Network guarantees anonymity to NICUs and persons who report events. This helped to overcome some of the factors that contributed to the culture of silence and fear that prevented reporting of adverse events. As far as we know, there has been no professional PtS network database for NICU in Egypt till now, and our database is the first.

The success of the incident report system is encouraging and enables us to move on and stand up against the traditional resistance to reporting. We still need national support to generalize the reporting system throughout the country. The role of incident reporting in improving PtS and patient culture had been described by several authors (18-19).

Regular alerts and indicators were extrapolated from issues that endanger safe practice. Developing indicators for PtS in the NICU is important for measurement of quality of practice (20).

The educational interactive forum was implemented to expand important items related to safety issues, it allows discussion and analysis by participants and experts; learning from shared experience is one of the methods that will lead to a reduction in medical errors.

The third work packages outputs achieved objectives 4, 5 and 6. Using our courses, we conducted $34 \mathrm{PtS}$ workshops, 11 PtS leadership workshops, 14 PtS scientific research workshops and 14 incident reporting workshops. To ensure the quality of the courses and manuals and the workshops, they were appraised by peer review and experts.

There has been a positive impact on staff behaviours, with improvement in attitudes and capacity-building professional skills among HCWs. They understand the nature of adverse events, medical errors, types of errors and triggers of errors, and this has enabled them to understand the safety issue and to value safe care. They act with more confidence to use the guidelines and the reporting system to apply a non-punitive safety culture and stop pointing fingers at others. Through the research courses, they built new, positive motivation to investigate root cause analysis of medical errors and consider solutions and improvement in care.

Health care workers are now more accurately writing and reading medical orders and double checking for drug dose, and are convinced by the directive for hand washing. The effect of training has been studied previously and was shown to be effective in reducing medical errors (21) and improving quality of health care (22).

The fourth work package achieved objective 4. We developed 15 neonatal guidelines; the Arabic translation was completed for 3 of these to help nurses and other HCWs. The lack of guidelines has been among the leading causes of medical errors; WHO has introduced several guidelines for global health problems (23).

Project activities allowed excellent dissemination of the project objectives and outputs to our stakeholders. The ENSTN has a strong link with society and aids parent 
education through education sessions and the webpage. Patient involvement in health care is important evidence of quality (24).

Several agreements were signed with related bodies to maintain the project activities. the Network has allowed cooperation between universities and the nonacademic sector, and nongovernmental societies and associations through founding and training workshops and the preparation of safety standards and guidelines.

There were unexpected outcomes with spin-off effects such as the development of a safety module for the fifth year paediatrics undergraduate students and introduction of a PtS module in the first year of undergraduate medical school in 2 of the partner universities. Similarly, PtS was implemented in the introduction course for the Egyptian neonatal fellowship programme; these fellows will be the specialized neonatologists of the future. The development of academic and practical hands-on training using simulators provided the opportunity to learn skills without committing errors. Furthermore, we ensured capacity-building of the trainers who are able to conduct courses in their work places; this overcame the lack of safety trainers and experts. Additionally, research related to PtS was conducted in form of 7 master's theses and one doctorate thesis.

We succeeded in obtaining a new grant to support the training and data incident reporting system from the
Academy of Science and Technology, and this has had a positive effect on the sustainability of the training and reporting activities.

\section{Conclusions}

Our achievements include NICU PtS standards for quality of care in neonatal units, 3 safety courses that suit different HCWs, the first national incident reporting system, a parent education booklet, safety training workshops and neonatal safety guidelines to aid in improvement of the PtS culture in our NICUs.

Finally we would like to report that improvements in PtS do not just happen. They need the right culture, good leadership, well trained HCWs and the right health systems. A strong safety culture requires: strong leadership, teamwork, accountability, understanding and moving from blaming individuals to recognizing the role of system factors in PtS, with the consideration that "no blame" is appropriate for many errors, however, certain errors demand accountability.

Efforts to sustain the project outcomes and outputs are highly appreciated by HCWs and the Ministry of Health and Population. They need to adopt the ENSTN safety standards, implement the incident reporting system, provide continuous regular training, update the guidelines and involve parents in the care of their babies.

\section{Acknowledgment}

Professor Dr Safaa ELMeneza, Al Azhar University; Professor Dr Michael Weindling, University of Liverpool; Professor Dr Tuuli Metsvaht, Professor Dr Heili Varendi, Tartu University; Professor Dr Mariam Abu Shady, Al Azhar University; Professor Dr Mohamed ELkalioby, Suez Canal University; Professor Dr Reda Bassiouny, Mansoura University; Professor Dr Mohamed Rewisha, Dr Ashraf Abu Hamama, Tanta University; Professor Dr Ehab ELbanna, Zagazig University; Dr Monika Surdu, Constanta University.

Funding: Five Egyptian and 3 European universities participated in the ENSTN project funded by Tempus grant 543823-TEMPUS-1-2013-1EG-TEMPUS-JPHES.

Competing interests: None declared.

\section{Réseau égyptien de formation en sécurité néonatale : un rêve, améliorer la culture de la sécurité des patients dans les unités néonatales de soins intensifs}

\section{Résumé}

Contexte : La sécurité des patients est essentielle pour fournir des soins de santé de qualité. Les agents de santé qui travaillent en unités néonatales de soins intensifs doivent relever des défis quotidiens pour garantir la sécurité des soins offerts à leurs patients et prévenir les erreurs médicales.

Objectifs : Développer le Réseau égyptien de formation en sécurité néonatale (ENSTN) pour promouvoir des pratiques médicales sûres dans les unités néonatales de soins intensifs en formant les agents de santé à la sécurité des patients et en favorisant une culture de la sécurité des patients.

Méthodes : Les réalisations du projet ENSTN ont été menées à bien dans le cadre de huit programmes d'activités. Le premier programme visait à établir des normes sur les connaissances et les compétences requises pour assurer la sécurité des pratiques en unités néonatales de soins intensifs, à définir le contenu des formations sur la sécurité des patients et à élaborer des normes. Les autres programmes portaient sur les domaines suivants : système de communication de l'information et base de données professionnels sur la sécurité des patients ; cohérence des programmes de formation et d'apprentissage partagés sur la sécurité des patients ; encadrement et recherche ; élaboration de protocoles et de directives afin de mettre en place des pratiques plus sûres et d'assurer leur pérennité; 
diffusion de messages du ENSTN ; confirmation des mesures de qualité et obtention de résultats satisfaisants ; viabilité des pratiques relatives à la sécurité des patients dans les unités néonatales de soins intensifs ; structuration du plan de gestion et facilitation des activités menées au titre des projets.

Résultats : Les activités suivantes ont été menées dans le cadre du projet : normes en anglais et en arabe sur la sécurité des patients dans les unités néonatales de soins intensifs; trois formations sur la sécurité des patients à l'intention des médecins, des personnels infirmiers et des autres agents de santé ; système électronique de communication de l'information et directives de l'ENSTN sur les erreurs médicales ; brochure destinée aux parents.

Conclusions : Il est essentiel d'organiser régulièrement des formations sur la sécurité des patients pour les agents de santé et d'appliquer les normes de l'ENSTN afin de réduire les erreurs médicales dans les unités néonatales de soins intensifs. Nous avons créé le premier système d'information confidentiel sur la sécurité des patients pour les unités néonatales de soins intensifs.

\section{الحديثي الولادة فية للتدريب على سلامة حديثي الو لادة: حلم لتعزيز ثقافة سلامة المرضى في وحدات الرعاية المركزّة} صفاء المنزه

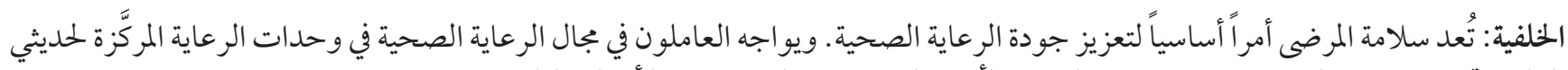

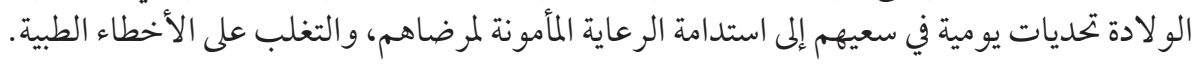

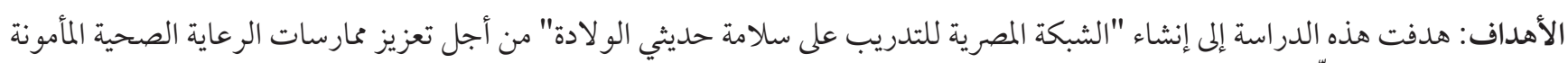

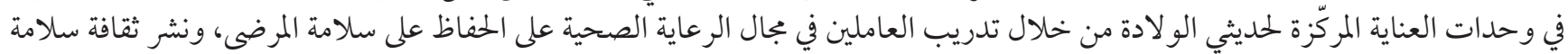
المرضى.

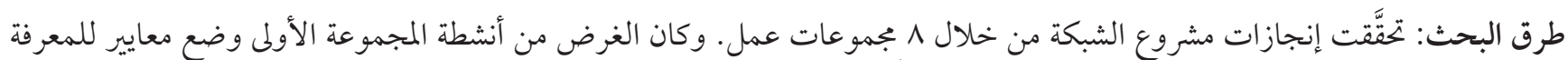

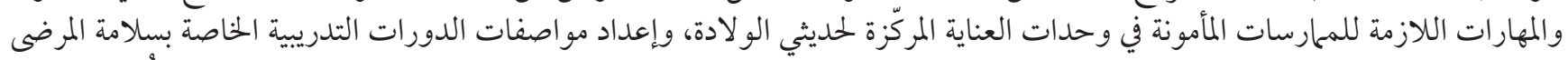

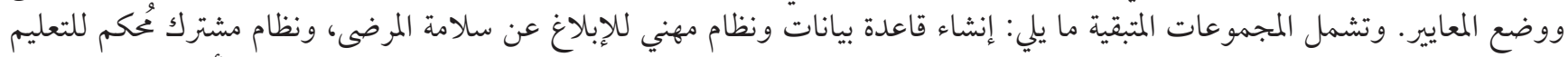

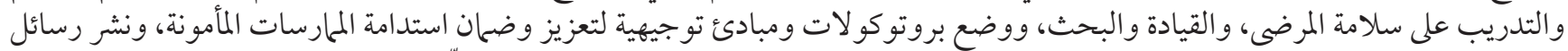

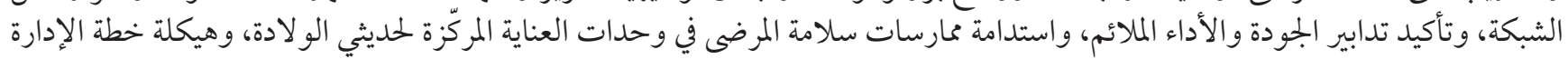

$$
\text { وتيسير أنشطة المشروع. }
$$

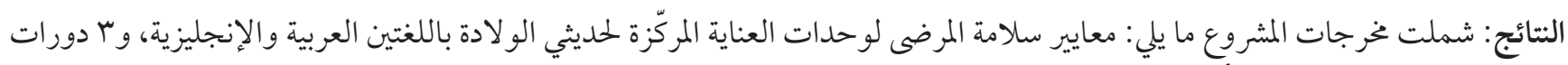

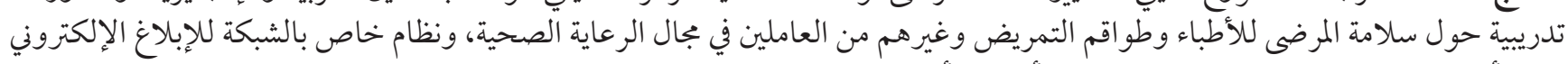

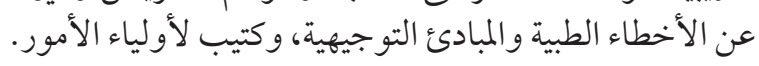

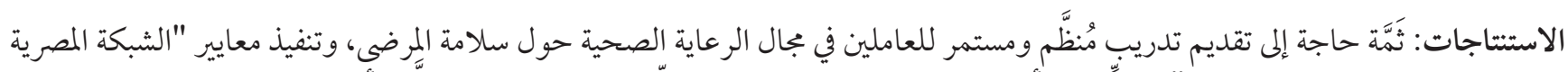

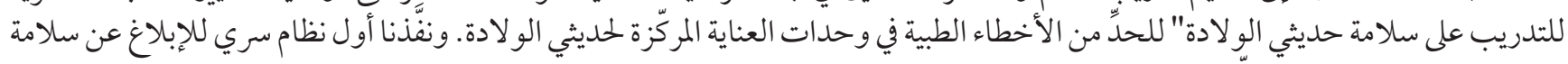

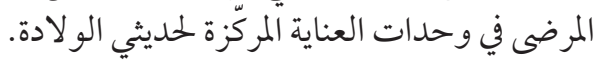

\section{References}

1. Coxon J and Rees J. Avoiding medical errors in general practice. Trends Urology Men's Health. July/August 2015;6(4):13-7. https://doi.org/10.1002/tre.467

2. Saedder AE, Lisby M, Nielsen LP, Rungby J, Andersen LV, Bonnerup D K, Brock B. Detection of patients at high risk of medication errors: development and validation of an algorithm. BCPT. 2016;118(2 ):143-6. https://doi.org/10.1111/bcpt.12473

3. Corrigan JM, Donaldson MS, Kohn LT, McKay T, Pike KC, Edington M; Committee on Quality Health Care in America, Institute of Medicine, et al. To err is human: building a safer health care system. Washington DC: National Academies Press, 2000 (https://www.nationalacademies.org/hmd/ /media/Files/Report\%20Files/1999/To-Err-is-\%20Human\%20/To\%20Err\%20\%20is\%20 \%20Human\%25\%20201999\%25\%2020\%20report\%2obrief.pdf, accessed 15 March 2018).

4. 10 facts on patient safety. Geneva: World Health Organization; 2018 (http://www.who.int/features/factfiles/patient_safety/en/, accessed 10 March 2018).

5. McMains V. Johns Hopkins study suggests medical errors are third leading cause of death in U.S. Physicians advocate for changes in how deaths are reported. Baltimore: Johns Hopkins Magazine HUB; 2016 (http://hub.jhu.edu/2016/05/03/medical-era rors-third-leading-causeof-death, accessed 18 February 2018). 
6. Makary MA, Daniel M. Medical error-the third leading cause of death in the US. BMJ. 2016;353:i2139. doi:https://doi.org/10.1136/ bmj.i2139

7. Patient safety. Data and statistics. Geneva: World Health Organization; 2018 (http://www.euro.who.int/en/health-topics/ Health-systems/patientsafety/data-and-statistics), accessed 1 April 2018).

8. Aly RE. Iatrogenic hazards in neonatal intensive care unit (thesis). Cairo: Al Azhar University; 2012 (https://www.researchgate. net/publication/324280519_Iatrogenic_Hazar ds_in_Neonatal_Intensive_Care_Unit, accessed March 2018)

9. Corrigan JM, Donaldson MS, Kohn LT, Maguire SK, Pike KC, Edington M, et al. Institute of Medicine (IOM). Crossing the quality chasm: a new health system for the 21st century. Washington DC: National Academy Press (US); 2001 (https://www. nationalacademies.org/hmd/ /media/Files/Report\%20Files/2001/Crossing-the-Quality-Chasm/\%20Quality\%25\%2020Chasm\%20 \%202001\%20\%25\%2020\%25\%2020report\%20brief.pdf, accessed 10 October 2017).

10. Institute of Medicine. Performance measurement: accelerating improvement. Washington, DC: National Academies Press; 2005 (https://www.nap.edu/read/11517/chapter/1, accessed 12 March 2018).

11. Suñol R, Vallejo P, Groene1 O, Escaramis G, Thompson A, Kutryba B, et al. Implementation of patient safety strategies in European hospitals. Qual Saf Health Care. 2009;18(Suppl. 1):i57-61. doi:10.1136/qshc.2008.029413

12. Report from the commission to the council on the basis of Member States' reports on the implementation of the council recommendation (2009/C 151/01) on patient safety, including the prevention and control of healthcare associated infections. Brussels: European Commission; 2012:1-15 (13.11.2012.COM 658 final) (https://ec.europa.eu/health//sites/health/files/patient_safety/docs/ council2009_report_en.pdf, accessed 12 March 2018).

13. Council recommendations of 9 June 2009 on patient safety, including the prevention and control of healthcare associated infections. Luxembourg: Official J European Union; 2009:1-6 (C 151/01) (https://ec.europa.eu/health//sites/health/files/patient_safety/ docs/council2009_en.pdf, accessed 1 March 12/2018)

14. Neonatal Expert Advisory Group. Neonatal care in Scotland: a quality framework. Edinburgh: Scottish Government publications; 2013 (www.gov.scot/Publications/2013/03/4910/7, accessed 1 March 2018).

15. Raju TN, Suresh G, Higgins RD. Patient safety in the context of neonatal intensive care. Pediatr Res. 2011;70(1):109-15. doi:10.1203/PDR.obo13e3182182853

16. National patient safety goals effective January 2018. Chicago: The Joint Commission; 2018 (https://www.jointcommission.org/ assets/1/6/NPSG_Chapter_HAP_Jan 2018.pdf, accessed 1 February /2018).

17. WHO patient safety curriculum guides for medical schools. Geneva: World Health Organization; 2009 (https://apps.who.int/iris/ bitstream/handle/10665/44091/9789241598316_eng.pdf?sequence=1\&isAllowed=y, accessed 1 February 2018).

18. Kamal Elden NM, Ismail A. The importance of medication errors reporting in improving the quality of clinical care services. Glob J Health Sci. 2016;8(8):243-9. doi:10.5539/gjhs.v8n8p243

19. Suresh G, Jeffrey D. Plsek HP, Gray J, Edwards WH, Shiono PH, et al. Voluntary anonymous reporting of medical errors for neonatal intensive care. Pediatrics 2004;113(6);1609. doi:10.1542/peds.113.6.1609

20. Kavanagh PL, Adams WG, Wang CJ. Quality indicators and quality assessment in child health. Arch Dis Child. 2009 Jun;94(6):458-63. doi:10.1136/adc.2008.137893

21. Campino A, Cruz Lopez-Herrera M, Heredia IL, Soler AV. Educational strategy to reduce medication errors in a neonatal intensive care unit. Acta Pædiatrica. 2009;98,(5):782-4. https://doi.org/10.1111/j.1651-2227.2009.01234.X

22. Lachmana P, Jayadeva A, Rahib M. The case for quality improvement in the neonatal intensive care unit. Early Human Development. 2014;90(11):719-5. https://doi.org/10.1016/j.earlhumdev.2014.09.003

23. WHO guidelines on patient safety. Geneva: World Health Organization; 2009 (https://www.who.int/publications/guidelines/ patient_safety/en/, accessed 12 October 2017).

24. Armstrong N, Herbert G, Aveling EL, Woods MD, Martin G. Optimizing patient involvement in quality improvement. Health Expect. 2013 Sep;16(3):e36-47. doi:10.1111/hex.12039 